\title{
Flight behaviour of the mānuka chafers, Pyronota festiva (Fabricius) and Pyronota setosa (Given) (Coleoptera: Melolonthinae), on the flipped soils of Cape Foulwind on the West Coast of New Zealand
}

\author{
Richard J. Townsend ${ }^{1, \star}$, Jessica E. Dunbar ${ }^{2}$ and Trevor A. Jackson ${ }^{1}$ \\ ${ }^{1}$ AgResearch, Lincoln Science Centre, Private Bag 4749, Christchurch, New Zealand \\ ${ }^{2}$ PGG Wrightson Ltd, 57 Waterloo Road, Hornby, Christchurch 8042, New Zealand \\ ${ }^{*}$ Corresponding author: richard.townsend@agresearch.co.nz
}

\begin{abstract}
Some species in the genus Pyronota are known to be serious pests of pasture. The establishment of new dairy pastures on recently flipped soils on Cape Foulwind, Buller provided a unique opportunity to investigate the flight behaviour and biology of Pyronota festiva and P. setosa from 2008-2012. Flight behaviour was monitored by fixed-vane interruption traps and by field observations. Adults of both species flew through late spring/ early summer (Nov-Dec) of each year and seasonal flight timing was consistent between years. Pyronota festiva flight timing and duration were similar to those previously reported in the literature and were slightly female dominated. Pyronota setosa flights started one to two weeks in advance of $P$. festiva and were dominated by males ( $>95 \%)$. Female $P$. setosa were rarely observed flying and were rarely caught in sweep-net sampling. Pyronota setosa beetles were never observed swarming or congregating and feeding on the foliage of mannuka. These differences in flight behaviour may help to explain the field observations that $P$. festiva can rapidly invade new pastures while $P$. setosa populations appear to spread more slowly.
\end{abstract}

Keywords Mānuka beetle, flight behaviour, dispersal, Buller, New Zealand.

\section{INTRODUCTION}

Mānuka beetle and mānuka chafer are common names for a complex of several species of endemic New Zealand Scarabaeidae belonging to the genus Pyronota in the sub family Melolonthinae. All are small beetles, less than $9 \mathrm{~mm}$ in length, generally green in colour and of diurnal habit (Given \& Hoy 1952, Brown 1963). The common name, mannuka beetle, reflects the fact that Pyronota beetles are often found congregating and feeding on the foliage of mānuka (Leptospermum scoparium) or kānuka (Kunzea ericoides). Brown (1963) reported that Pyronota beetles were also observed in the field congregating and feeding on endemic matagouri (Discaria toumatou) and exotic invasive briar (Rosa rubiginosa). There are three relatively common Pyronota species,
P. festiva, P. laeta and P. edwardsi, and all are widely distributed throughout New Zealand (Brown 1963). Two of these, P. festiva and $P$. laeta have been implicated as causing pasture damage through larval feeding on the roots of sown grass and clover species similar to that caused by the endemic New Zealand grass grub Costelytra zealandica (Thomson et al. 1979). In contrast, Pyronota setosa is a relatively rare species, reported by Brown (1963) as having a mainly littoral distribution and most often collected from sandy soils in coastal scrubland areas. Pyronota setosa had not been reported in the scientific literature as a significant pest of pasture.

In the early 2000s, areas of relatively unproductive pakihi soils on Cape Foulwind were 
'flipped' (inverting and mixing the original topsoil and subsoils to a depth of 1-2m and breaking up any iron pan to improve drainage using hydraulic excavators) to sow new pastures for dairy cattle. During this process, large areas of well-drained sandy soils were formed, which provided an ideal habitat for a range of pasture pest species, including porina (Wiseana spp.) and mānuka beetle (Jackson et al. 2012). Unexpectedly, two species of mānuka beetle, $P$. festiva and P. setosa, (but not $P$. laeta) were found to be contributing to the ongoing widespread pasture damage on the 'flipped' soils of Cape Foulwind (Townsend et al. 2010, Jackson et al. 2012, Zydenbos et al. 2013). While developing a management system for this pest complex, the flight behaviour and general biology of mānuka beetles were monitored over four flight seasons in this newly created and highly modified environment. The first season (2008-09) provided baseline data for both species. The flight monitoring programme for the following three seasons (2009-10 to 201112) was designed to clarify whether the flight patterns of the two mānuka beetle species varied within and between seasons.

\section{MATERIALS AND METHODS}

Cape Foulwind, situated in the Buller region on the west coast of the South Island, contains approximately 3000 ha of dairy pasture established on 'flipped' soils. These pastures, mainly standard ryegrass clover dairy mixes, are sited on flat to rolling topography 20-40 m above sea level and are all situated within approximately $10 \mathrm{~km}$ of the coast. The study sites were located within a $5-\mathrm{km}$ radius of the centre of this area. Rainfall on Cape Foulwind averages $2274 \mathrm{~mm}$ per year (NIWA 2015).

Flight interruption traps were constructed from two $40 \mathrm{~cm}$ squares of clear 3-mm acrylic sheeting, each divided with a central $20-\mathrm{cm}$ deep slot, fitted together at right angles. The interruption vanes were then fixed upright on $2.5-\mathrm{cm}$ square bird mesh covering $8-\mathrm{cm}$ deep water-filled troughs. The traps were designed to replicate the vane impaction traps used by Thomson et al. (1979) to monitor mānuka beetle
(P. festiva and P. laeta) flight at Okato in Taranaki. Field observations of flight behaviour and general biology of the two species of Pyronota were made by one the authors who was on site throughout the four seasons of flight monitoring. Sweep-net sampling of the pastures surrounding the trap sites was carried several times during the study usually in calm warm conditions at the peak of the flights. Beetles caught were identified to species and sex and observations of the occurrence of mating pairs were noted. Small numbers of female beetles, from a range of dates from flight trap samples, were dissected under binocular microscopes to determine presence or absence of mature eggs. A concurrent unpublished study monitored larval populations $4-5$ times a year over four years at these sites.

\section{Flight monitoring 2008-09}

In mid-November 2008, three sets of paired traps were placed close together, 5-10 m apart, in each of three paddocks (\#24, \#33 and \#51) on Basset Dairy Farm (Landcorp Farming Ltd), Wilsons Lead Rd, Cape Foulwind. One of each pair of traps had the collecting surface set at grazed sward height, (approx. $10 \mathrm{~cm}$; ground trap), while the other trap had the collecting surface set $1 \mathrm{~m}$ above ground level. During normal daytime flight activity, mānuka beetle adults that hit the flight interruption vanes fell into the water in the troughs and were unable to escape. Traps were inspected and cleared every 2-4 days and all trapped beetles were collected and frozen. They were for later identified to species and sex.

\section{Flight monitoring 2009-10, 2010-11 and 2011-12}

In 2009-10, two sets of paired traps were placed in the same paddocks as above and on four other properties with similar pastures within the main area of flipped land on Cape Foulwind. During the 2010-11 and 2011-12 flight seasons, single pairs of traps were deployed on the same sites monitored in 2009-10. Traps were deployed from mid-October, a month earlier than during the 2008-9 monitoring, until the end February. Traps were inspected and cleared every $2-4$ days 
and all trapped beetles were collected and frozen They were later identified to species.

\section{Statistical analyses}

Analysis of the timing for 5\%, 50\% and 95\% of the cumulative flight to occur was by analysis of variance (ANOVA) using a single factor, Year (three levels 2009-10, 2010-11 and 2011-12) and was carried out separately for each species using Minitab software version 16. Overall means of the three individual-year species means were compared using a two-sample t test.

\section{RESULTS AND DISCUSSION}

\section{Flight behaviour: 2008-09}

Data reported in Figure 1 represents cumulative percentage trap catches for each of the two Pyronota species found in each paddock. Beetles appeared in the interruption traps as soon as the traps were deployed in mid-November 2008. This observation suggests that in all three paddocks, there was some flight prior to the start of monitoring, particularly of $P$. setosa where 14$28 \%$ of the cumulative seasonal catch occurred on the first day of monitoring. Pyronota setosa flight started and finished earlier than $P$. festiva flight during this flight season. On average, across the three sites $50 \%$ percent of the total beetle catch had occurred by the beginning of the second week of December. Beetles, mainly late flying females, continued to be caught until late February 2009 but only in very small numbers during the last month of the flight.

Details of the 2008-9 trapping data, aggregated across all three sites by species and sex are shown in Table 1. Pyronota festiva seasonal flight patterns were broadly similar in both duration and timing to those reported by Thomson et al. (1979) for P. festiva flight at Okato in Taranaki (Table 1). During the first half of the 2008-9 flight season, both sexes of $P$. festiva were trapped at similar rates (51\% ${ }^{\lambda}: 49 \%$ \%) again similar to Thomson's findings. However, male $P$. festiva in the Taranaki study were caught mainly in ground traps $(67 \%)$ while in this study most males (70\%) were caught in the $1-\mathrm{m}$ traps (Table 2). Reasons for this difference are not clear but may be due to differences in topography
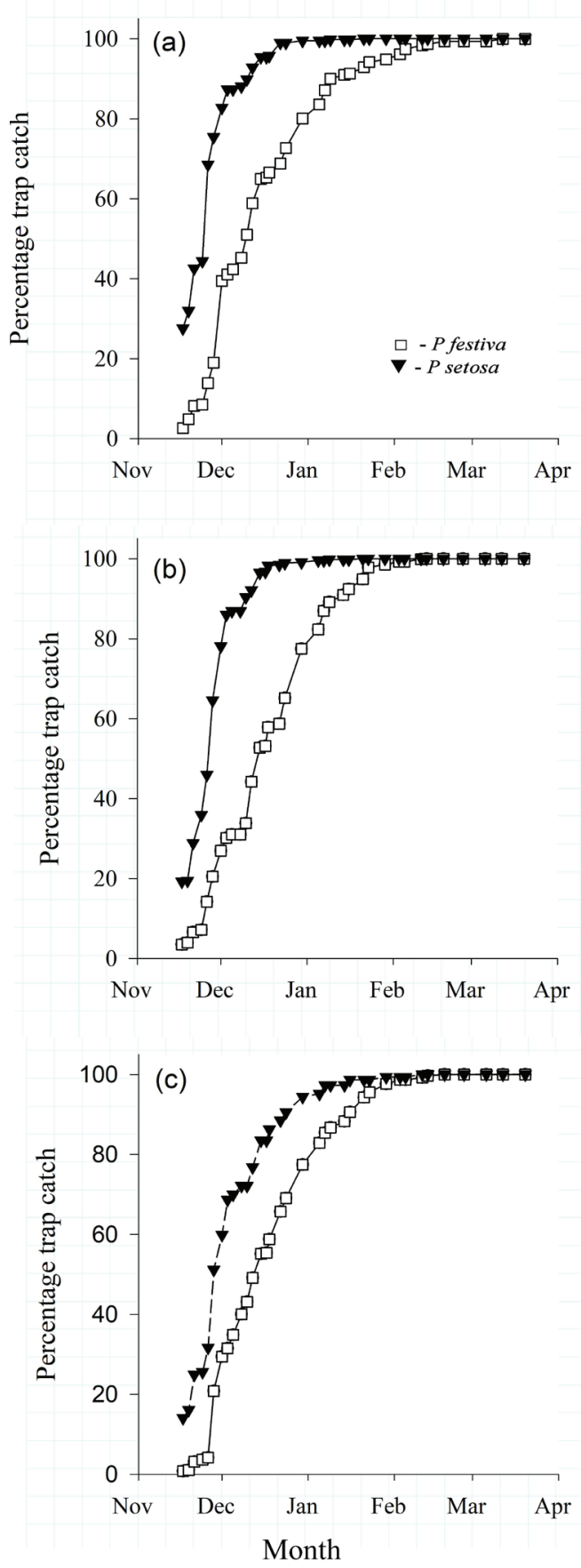

Figure 1 Cumulative trap catches of Pyronota festiva and P. setosa during 2008-09 flight on Bassets Farm, Cape Foulwind. Paddock 24 (a); Paddock 33 (b); and Paddock 51 (c). 
Table 1 Total numbers and percentage catch by species and sex aggregated for both trapping heights and sample dates for trapping periods across all three sites during the 2008-09 flight season.

\begin{tabular}{llrrrrrr}
\hline \multirow{2}{*}{$\begin{array}{l}\text { Trapping } \\
\text { period }\end{array}$} & \multicolumn{3}{c}{ Pyronota festiva } & \multicolumn{3}{c}{ Pyronota setosa } \\
\cline { 3 - 8 } Nov-7 Dec & No. trapped & 156 & 147 & 303 & 649 & 18 & 667 \\
& \% sex & 51 & 49 & & 97 & 3 & \\
7 Dec-Feb & No. trapped & 102 & 273 & 375 & 46 & 16 & 62 \\
& \% sex & 27 & 73 & & 74 & 26 & \\
\hline Total & No. trapped & 258 & 420 & 678 & 695 & 34 & 729 \\
& \% sex & 38 & 62 & & 95 & 5 & \\
\hline
\end{tabular}

between the two trapping environments or possibly reflect behavioural factors caused by the large differences in $P$. festiva population densities at the two sites $\left(123 / \mathrm{m}^{2}\right.$ at Okato, $310-670 / \mathrm{m}^{2}$ at Cape Foulwind). Female P. festiva dominated the catch $(27 \%$ : $: 73 \%$ ) $)$ during the second half of the 2008-9 flight season on Cape Foulwind. Unfortunately, Thomson (1979) did not report on this aspect of $P$. festiva flight at Okato. The majority of these females, $63 \%$ (Table 2), were caught in traps set 1-m above ground level with the remainder collected from the ground level traps.

The $P$. setosa data presented in Table 1 show important differences in flight behaviour compared to both $P$. festiva in this study and observations previously reported in the literature for any Pyronota species. The vast majority (97\%) of the P. setosa trapped during the first half of the flight season (Nov-7 Dec) were males, 649 individuals, with only 18 females (3\%) caught in the flight interruption traps. These early males accounted for $95 \%$ of the cumulative $P$. setosa catch over the entire flight season (Table 1). Of the total $P$. setosa male catch, $86 \%$ were found in ground traps and $14 \%$ in the traps set at $1-\mathrm{m}$ above ground (Table 2). The few female P. setosa caught in the flight traps were found in similar numbers throughout the flight season (Table 1) and most (68\%, Table 2) were found in traps set $1-\mathrm{m}$ above ground. This was similar to the height distribution of female $P$. festiva trap catches.
Flight behaviour: 2009-10, 2010-11 and

\section{1-12}

The mean dates for the cumulative 5\%, 50\% and $95 \%$ trap catches for each species averaged across the seven sites monitored are provided in Table 3 and show the standard error of the mean (SEM) and 95\% confidence interval ranges for each date. As trap monitoring started a month earlier for these three flight seasons, compared with 2008-09, the earliest flights of both species were able to be recorded, with the first records for each species either being zero or contributing only a small percentage (1-2\%) of the overall catch. When the overall means across the three flight seasons were compared, $P$. setosa flight started and finished earlier than $P$. festiva (twosample $t$ tests, $5 \%$ cumulative flight $\mathrm{P}=0.008$, 95\% cumulative flight $\mathrm{P}=0.001$ ). These differences between the two Pyronota species appear to be attributable to the early season male-dominated $P$. setosa flights and, in the latter half of the flight season, by the female-dominated $P$. festiva flight trap catches. Six other sites in the area were also monitored and produced similar results but the data are not presented as traps on these sites were cleared less regularly.

The $50 \%$ cumulative flight dates for the two species were not statistically different $(\mathrm{P}>0.05)$. Dates by which $50 \%$ cumulative flight occurred only varied from the three-year average for each species by approximately one week ( 8 days for P. festiva and 6 days for P. setosa). The closely related New Zealand melolonthid Costelytra 
Table 2 Effect of trap height effect on percentage catch by species and sex aggregated across all three monitoring sites and sample dates for trapping periods during the 2008-09 flight season.

\begin{tabular}{|c|c|c|c|c|c|}
\hline \multirow{2}{*}{$\begin{array}{l}\text { Trapping } \\
\text { period }\end{array}$} & & \multirow{2}{*}{$\frac{P . \text { festiva }}{\pi}$} & \multicolumn{3}{|c|}{ P. setosa } \\
\hline & & & q & $\hat{0}$ & q \\
\hline \multirow[t]{2}{*}{ Nov-7 Dec } & Ground trap & 32 & 31 & 87 & 22 \\
\hline & 1-m trap & 68 & 69 & 13 & 78 \\
\hline \multirow[t]{2}{*}{7 Dec-Feb } & Ground trap & 26 & 40 & 65 & 44 \\
\hline & 1-m trap & 74 & 60 & 35 & 56 \\
\hline \multirow[t]{2}{*}{ Total } & Ground trap & 30 & 37 & 86 & 32 \\
\hline & 1-m trap & 70 & 63 & 14 & 68 \\
\hline
\end{tabular}

Table 3 Mean ( \pm SEM) cumulative flight dates averaged over three flight seasons (2009-2012) and seven sites for the two manuka beetle species plus the $95 \%$ confidence interval.

\begin{tabular}{llccc}
\hline & Species & $\begin{array}{l}\text { Mean flight } \\
\text { date }\end{array}$ & SEM (days) & $\begin{array}{l}\text { 95\% confidence intervals } \\
\text { for mean flight dates }\end{array}$ \\
\hline 5\% cumulative & P. festiva & $14 / 11$ & \pm 1.4 & $11 / 11 \sim 17 / 11$ \\
flight & P. setosa & $9 / 11$ & \pm 0.9 & $7 / 11 \sim 11 / 11$ \\
$50 \%$ cumulative & P. festiva & $30 / 11$ & \pm 1.8 & $26 / 11 \sim 4 / 12$ \\
flight & P. setosa & $26 / 11$ & \pm 1.4 & $23 / 11 \sim 29 / 11$ \\
$95 \%$ cumulative & P. festiva & $23 / 12$ & \pm 2.3 & $18 / 12 \sim 28 / 12$ \\
flight & P. setosa & $12 / 12$ & \pm 2.4 & $7 / 12 \sim 17 / 12$ \\
\hline
\end{tabular}

zealandica also exhibits relatively stable annual flight patterns within discrete geographical locations (Henzell et al. 1980).

Although the timing of the $50 \%$ cumulative flight for the two species is very similar there is a 30-and 39-day spread ( $P$. setosa and P. festiva respectively) between the cumulative $5 \%$ and 95\% mean flight dates for the two species (Table 3). This suggests that attempts to use insecticides to control the adult stage of these populations would be prohibitively expensive due to the number of spray applications which would be necessary.

As both sexes of $P$. festiva were equally represented in early season flights, it is possible these flights serve as a means to facilitate mating by enabling aggregation of the sexes particularly on taller vegetation within pasture. Field observations made during these studies suggest that, when aggregations of beetles occurred on the taller plants (usually weed species) mating pairs were observed more often than elsewhere in the pasture. Dissections of $P$. festiva females sourced from the flight intercept traps commonly showed mated females were flying with a full complement of mature eggs within the pasture environment. Although P. festiva were often observed mating and feeding on the sparse amount of mānuka bush within the study area, repeated field observations over the four-year study period failed to note concerted directional flights to or from mānuka within the wider study area. Cumber \& Cowie (1954) and Barratt (1983) noted mating and feeding on mānuka did not appear to be a prerequisite for the buildup of pasture-damaging mānuka beetle larval populations. Sampling for mānuka beetle larvae in pastures surrounding the flight traps in these studies repeatedly showed that $P$. festiva larvae were widely distributed within those pastures. 
Throughout the four seasons of flight monitoring, populations of $P$. festiva larvae were frequently observed causing severe pasture damage in the wider study area hundreds of metres distant from any significant area of mānuka bush. Young, newly establishing pastures within the study area were rapidly infested by $P$. festiva, which suggests that $P$. festiva females travel widely while ovipositing and that dispersal is a major function of their flight behaviour.

Very few female $P$. setosa were caught in the flight traps in 2008-09 (Table 1). Monitoring results from the same sites during 2009-10, where trapping started a month earlier, supported this finding with females representing only $2 \%$ of the total $P$. setosa catch across those three sites in the 2009-10 flight season (data not presented). Female $P$. setosa were always difficult to find and observe at any time in the Cape Foulwind dairy pastures. Sweep-net sampling of weeds and pasture at various heights repeatedly failed to collect $P$. setosa females in significant numbers while both $P$. setosa males and both males and females of $P$. festiva were easily collected whenever sweep-net sampling was carried out during peak flights. A preliminary study (unpublished data.) indicated that caged $P$. setosa females attract males which suggests they produce a sex pheromone. These observations, and the fact that males were caught mainly in ground traps early in the flight season (Table 2), suggest that $P$. setosa flights are primarily mate-searching flights by males as they attempt to find females hidden within the pasture sward. Pyronota setosa were never found aggregating or mating and feeding on mānuka during this study.

Field sampling for Pyronota spp. larvae in dairy pastures surrounding the flight trap sites on Cape Foulwind repeatedly showed P. setosa larval populations to be much more aggregated than those of $P$. festiva (unpublished data). The aggregation of the larval populations and comparative lack of female $P$. setosa flight could account for the slow observed rate of dispersal of $P$. setosa into new habitats during these studies in comparison with the rapid colonisation behaviour exhibited by $P$. festiva.

\section{ACKNOWLEDGEMENTS}

The authors thank Chikako van Koten (AgResearch) for the statistical analysis of the flight periodicity data. This research was supported by the Ministry for Primary Industries Sustainable Farming Fund project 401443 and by New Zealand's Ministry of Science and Innovation through contract LINX0304, Ecosystems Bioprotection.

\section{REFERENCES}

Barratt BIP 1983. Distribution survey of soil insects at Millers Flat, Central Otago. New Zealand Journal of Experimental Agriculture 11: 83-87.

Brown JG 1963. Biology and taxonomy of the genus Pyronota Bois. (Melolonthinae, Coleoptera). University of Canterbury, New Zealand Lincoln College.

Cumber R, Cowie J 1954. Grass grub populations in the soils of the Manawatu sand country. New Zealand Journal of Science and Technology 35: 465-470.

Given BB, Hoy J 1952. A revision of the Melolonthinae of New Zealand. New Zealand Department of Scientific and Industrial Research Bulletin 102: 1-137.

Henzell R, Lauren D, Cox N, Crosby T, Pottinger R 1980. Monitoring Costelytra zealandica flight with sex attractant traps (Coleoptera: Scarabaeidae). Proceedings of the 2nd Australasian Conference on Grassland Invertebrate Ecology. Palmerston North, New Zealand 22-26 May 1978. Pp. 125-128.

Jackson TA, Townsend RJ, Dunbar JE, Ferguson CM, Marshall SDG, Zydenbos SM 2012. Anticipating the unexpected- managing pasture pest outbreaks after large-scale land conversion. Proceedings of the New Zealand Grassland Association 74: 147-152.

Thomson NA, Miln AJ, Kain WM 1979. Biology of manuka beetle in Taranaki. Proceedings of the New Zealand Weed and Pest Control Conference 1979 32: 80-85.

Townsend RJ, Nelson TL, Jackson TA 2010. Beauveria brongniartii - a potential biocontrol agent for use against manuka beetle larvae 
damaging dairy pastures on Cape Foulwind. New Zealand Plant Protection. 63: 224-228.

Zydenbos SM, Ferguson CM, Townsend RJ, Dunbar JE, Peoples S, Willoughby BE, Lane PMS, Jackson TA 2013. Decision tools for managing insect pest outbreaks in pastures. Proceedings of the New Zealand Grassland Association 75: 103-112. 